Case Report

\title{
Case report of malignant peripheral nerve sheath tumor of parotid in a patient with neurofibromatosis type 1
}

\author{
Anuradha P.*, Bathi Reddy, Suhail Gaur
}

Department of ENT, Manipal Hospital, Bangalore, Karnataka, India

Received: 15 June 2021

Revised: 13 October 2021

Accepted: 12 November 2021

\author{
*Correspondence: \\ Dr. Anuradha P., \\ E-mail: Anu.jamuna@gmail.com
}

Copyright: $@$ the author(s), publisher and licensee Medip Academy. This is an open-access article distributed under the terms of the Creative Commons Attribution Non-Commercial License, which permits unrestricted non-commercial use, distribution, and reproduction in any medium, provided the original work is properly cited.

\begin{abstract}
Malignant peripheral nerve sheath tumor (MPNST) refers to spindle cell sarcomas arising from or separating in the direction of cells of the peripheral nerve sheath. The MPNST of the parotid gland is an extremely rare tumor, accounts for $<5 \%$ of all soft tissue sarcomas, and carries a poor prognosis. Diagnosis of MPNSTs is usually based on histopathology aided by IHC, which reflects the Schwann cell differentiation in this neoplasm. Approximately 50-90\% of MPNSTs are positive for S-100 protein. A 56-year-old male presented with right parotid swelling for 3 months and incomplete right eye closure. The patient was diagnosed with neurofibromatosis 1 (NF-1) and pulmonary tuberculosis in the past. On Examination, a hard, tender swelling measuring $5 \times 4 \mathrm{~cm}$ involving the right parotid gland and right grade 2 LMN facial palsy was noted. Histopathology was suggestive of a MPNST.
\end{abstract}

Keywords: Parotid, Facial nerve, NF1, Malignant nerve sheath tumor

\section{INTRODUCTION}

Mesenchymal tumors comprise about $2 \%$ to $5 \%$ of all salivary gland tumors with over $95 \%$ involving the major salivary glands. Malignant tumors are outnumbered by benign mesenchymal tumors. ${ }^{1}$ The ratio of benign to malignant lesions described in the literature is $2.4: 1$ to $18: 1$. The incidence of MPNST in the parotid gland is very rare, about $0.01 \%$. The differential diagnosis includes other spindle cell tumors of parotid like myoepithelial carcinoma, spindle cell carcinoma, malignant melanoma, and fibrosarcoma. These are easily ruled out when histomorphological characteristics are combined with immunohistochemistry features, and hence, awareness of these is imperative for differentiating this rare entity from other spindle cell tumors. Wide surgical excision with possible preservation of facial nerve along with neck dissection and adjuvant chemoradiotherapy is the mainstay of treatment. MPNST of the parotid gland has a very aggressive course and a very bad prognosis with a survival rate of 5 to 7 years. We report an MPNST of the parotid gland in a 45-yearold male and review its diagnostic details including the histopathologic and immunohistochemical features.

\section{CASE REPORT}

A 56-year-old male presented with right parotid swelling for 3 months and incomplete right eye closure. The patient was diagnosed with NF1 and pulmonary tuberculosis in the past. On examination, a hard, tender swelling measuring $5 \times 4 \mathrm{~cm}$ involving the right parotid gland and right grade 2 LMN facial palsy was noted. MRI scan was done and was suggestive of the diffusely enlarged parotid gland with multiple small rounded to oval mildly $\mathrm{T} 1$ isointense, $\mathrm{T} 2$ fat suppression grey signal intensity lesions in the right parotid gland. FNAC was suggestive of a MPNST. He underwent right total radical parotidectomy. Histopathology was suggestive of a MPNST. Post-op chemoradiotherapy was started. 


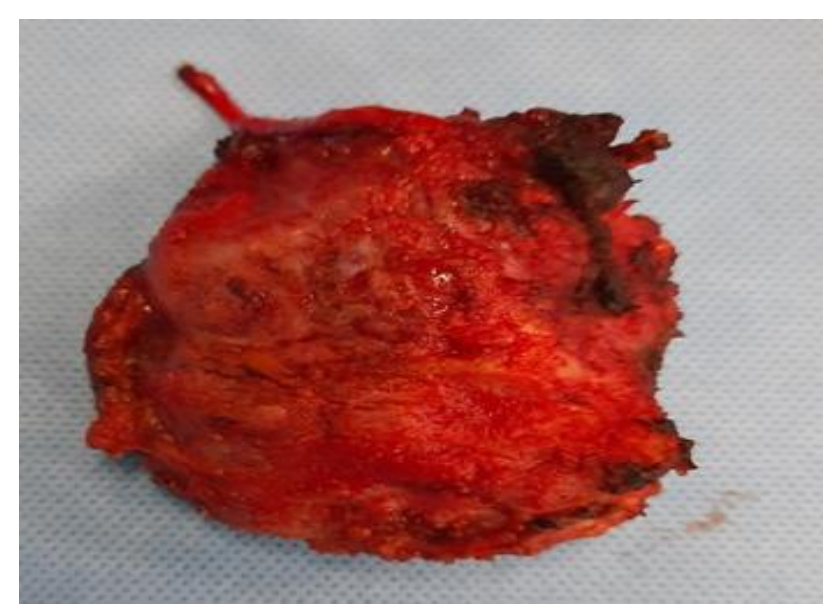

Figure 1: Total radical parotidectomy specimen.

\section{DISCUSSION}

The association between MPNST and NF-1 is well known. Initial reports that were based on specialist series found high risks of MPNST in NF-1. ${ }^{2}$ Etiopathogenesis of MPNST with NF-1 is believed to be associated with loss of chromosomal arm $17 \mathrm{q}$ sequence including complete inactivation of NF-1 gene. ${ }^{3}$ Because of invasive growth, the propensity to metastasize, and limited sensitivity to chemotherapy and radiation, MPNST has a guarded to poor prognosis. Five-year survival rates of only $20-50 \%$ indicate an urgent need for improved therapeutic approaches

A sarcoma is assumed to be a MPNST if one of the 3 criteria are met, with tumor arises from a peripheral nerve, tumor arises from a pre-existing benign nerve sheath tumor, neurofibroma, and or tumor displaying a constellation of histological features of Schwann cell differentiation. ${ }^{4}$ There is a histological spectrum of peripheral nerve sheath tumors ranging from benign to malignant, and it is often possible to distinguish between high-grade and low-grade tumors. However, a significant number of tumors, the so-called "atypical neurofibromas" do not fit into any defined grading system. These may be locally aggressive but are less likely to metastasize. In addition, there are a few histologically low-grade tumors that behave aggressively. The application of molecular techniques to determine the gene expression profiles of gene expression in these tumors may help pathologists to predict biological behavior and the outcome more accurately. The correlation with new imaging techniques may also help to resolve this issue

MPNSTs are uncommon sarcomas of Schwann cell or fibroblastic derivation which occasionally show histologic evidence of focal divergent differentiation to rhabdomyosarcoma, osteosarcoma, chondrosarcoma, angiosarcoma, epithelial elements, or a combination. ${ }^{5}$ Diagnosis of MPNSTs is usually based on histopathology aided by IHC, which reflects the Schwann cell differentiation in this neoplasm. Approximately 50-90\% of MPNSTs are positive for S-100 protein. The present case displayed all histologic and immunohistochemistry features suggestive of MPNST. Focal positivity for S 100 and negativity for SMA and CK ruled out the possibility of sarcomatoid or spindle cell carcinoma in the present case. ${ }^{6}$ Certain histological variants such as epithelioid, glandular, rhabdomyosarcomata's (malignant triton tumor), pigmented, and perineural have also been described in the literature but have little effect on prognosis.

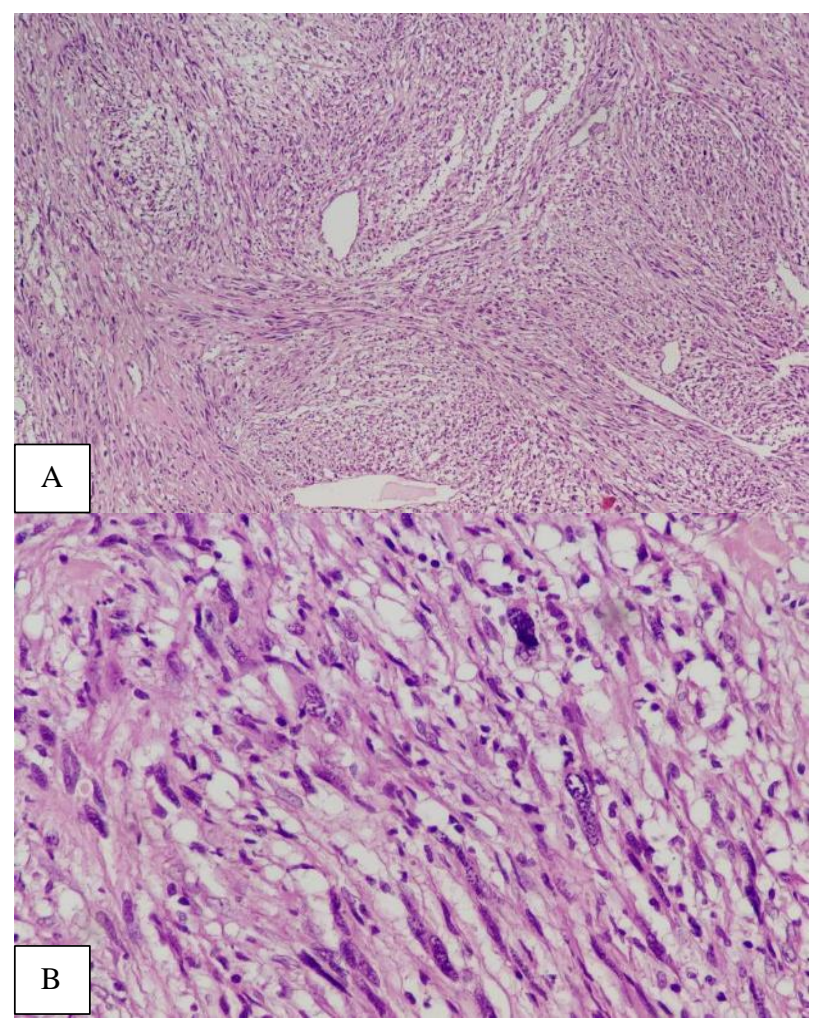

Figure 2 (A and B): MPNST cells with focal bizarre nuclei and osteoclastic giant cells.

\section{CONCLUSION}

The MPNSTs arising as parotid mass are very rare. MPNST is a devastating complication of NF-1, which should be managed by multidisciplinary teams of clinicians with expertise in the diagnosis and treatment of this disease. Pathologists and surgeons should keep this in mind when dealing with a patient with a parotid mass. Wide surgical resection and adjuvant chemoradiotherapy are the choices of treatment.

\section{Funding: No funding sources \\ Conflict of interest: None declared \\ Ethical approval: Not required}

\section{REFERENCES}

1. Daga G, Paul R, Mandal G, Kumar R. Malignant Peripheral Nerve Sheath Tumor of the Parotid Gland. Indian J Surg Oncol. 2018;9(4):629-32. 
2. Evans DG, Baser ME, McGaughran J, Sharif S, Howard E, Moran A. Malignant peripheral nerve sheath tumors in neurofibromatosis 1 . J Med Genet. 2002;39(5):311-4.

3. King AA, Debaun MR, Riccardi VM, Gutmann DH. Malignant peripheral nerve sheath tumors in neurofibromatosis 1. Am J Med Genet. 2000;93(5):388-92.

4. Ferner RE, Gutmann DH. International consensus statement on malignant peripheral nerve sheath tumors in neurofibromatosis. Cancer Res. 2002;62(5):1573-7.
5. Ducatman BS, Scheithauer BW. Malignant peripheral nerve sheath tumors with divergent differentiation. Cancer. 1984;54(6):1049-57.

6. Gupta G, Mammis A, Maniker A. Malignant peripheral nerve sheath tumors. Neurosurg Clin N Am. 2008;19(4):533-43.

Cite this article as: Anuradha $\mathrm{P}$, Reddy B, Gaur S. Case report of malignant peripheral nerve sheath tumor of parotid in a patient with neurofibromatosis type 1. Int J Otorhinolaryngol Head Neck Surg 2021;7:1927-9. 